\title{
O uso do cinema como estratégia pedagógica para o ensino de ciências e de biologia: o que pensam alguns professores da região metropolitana de Belo Horizonte
}

\author{
The use of the cinema as a pedagogic strategy for teaching science \\ and biology: what think some teachers in the metropolitan area of \\ Belo Horizonte
}

\author{
Marcelo Diniz Monteiro de Barros ${ }^{1}$ \\ Mariana Girasole² \\ Priscilla Guimarães Zanella ${ }^{3}$
}

\section{RESUMO}

O trabalho aborda a utilização do cinema como estratégia pedagógica por professores do Ensino de Ciências e de Biologia, em escolas públicas e particulares na Região Metropolitana de Belo Horizonte. Além de avaliar como essa metodologia é utilizada pelos educadores do Ensino Fundamental e Ensino Médio, o estudo disponibiliza um guia de filmes como sugestões para aprimorar o uso do cinema como estratégia pedagógica. Apesar de todas as transformações que vêm ocorrendo no mundo do conhecimento e da educação, o cinema ainda é pouco valorizado pela escola, principalmente pelo fato de não ser compreendido por todos os alunos e professores como estratégia pedagógica séria e planejada.

Palavras-chave: ensino de ciências, ensino de biologia, cinema como estratégia pedagógica.

\section{ABSTRACT}

This paper approaches the use of cinema as a pedagogical strategy for teachers of science and biology, in public and private schools in the metropolitan area of Belo Horizonte. In addition to assessing how this methodology is used by educators of elementary school and high school, the study provides a guide to films such as suggestions for improving the use of cinema as a pedagogical strategy. Despite all the transformations occurring in the world of knowledge and education, the film is still not valued by the school, mainly because of not being understood by all students and teachers as a pedagogical strategy seriously and planned.

Keywords: science education, biology education, film as a pedagogical strategy.

\footnotetext{
1 - Departamento de Ciências Biológicas da Pontifícia Universidade Católica de Minas Gerais,

2- Bacharel e Licenciada em Ciências Biológicas pela Pontifícia Universidade Católica de Minas Gerais.

3 - Mestranda em Ensino de Ciências pela Pontifícia Universidade Católica de Minas Gerais
} 


\section{INTRODUÇÃO}

O presente trabalho aborda a utilização do cinema como estratégia pedagógica por professores do Ensino de Ciências e de Biologia, em escolas públicas e particulares da Região Metropolitana de Belo Horizonte.

Um dos principais objetivos norteadores desse trabalho é incentivar a utilização do cinema como estratégia pedagógica de uma forma mais eficaz e frequente e, através disto, promover a melhoria da qualidade de ensino oferecida a crianças e adolescentes. Para isso foi preciso avaliar como essa estratégia pedagógica é utilizada pelos educadores do Ensino Fundamental e Ensino Médio. Como produto final, o presente trabalho disponibiliza uma lista com 83 títulos de filmes comerciais que podem ser utilizados nas salas de aula como estratégia de ensino. No desenvolvimento dessa pesquisa também foram abordadas as vantagens e dificuldades que surgem ao longo do processo ensino/aprendizagem quando se utiliza a estratégia em questão.

Além de apresentarmos a possibilidade do uso do cinema como estratégia pedagógica e de como os profissionais a utilizam, é necessário nos atermos a outras questões, como: esses profissionais recebem a devida capacitação para desenvolver esse tipo de estratégia? Qual a melhor forma de se relacionar a arte do cinema com o conteúdo que se pretende ensinar?

Essas questões podem ter várias respostas quando o principal objeto de pesquisa é o ser humano. Entretanto, embora cada profissional tenha suas particularidades ao ensinar, é necessário sabermos se de fato o objetivo esperado está sendo alcançado, de forma a acrescentar ao crescimento cognitivo e integral desses estudantes.

A preocupação com a devida formação dos alunos e o interesse em defender o uso do cinema como estratégia pedagógica eficaz no processo de ensino/aprendizagem são as principais justificativas para a escolha do tema desse trabalho.

\section{O USO DO CINEMA COMO ESTRATÉGIA PEDAGÓGICA}

Com o desenvolvimento dos meios de comunicação de massa, sobretudo do cinema, TV e vídeo, a imagem acabou por se tornar um elemento central na vida dos homens, como também um importante veículo de difusão do conhecimento na sociedade atual (CARVALHO, 1998).

Diante desse contexto o uso do cinema como estratégia pedagógica e educacional pode ser de grande valia para o processo de ensino e aprendizagem, não somente para a apresentação dos conteúdos exigidos na escola, mas também para a formação do caráter integral do individuo.

“... da mesma forma que a iniciação à linguagem literária, a iniciação à linguagem do cinema é uma aprendizagem” (FUZELLIER, 1964).

De acordo com Silva e Citelli (2004), ainda que o cinema articule, em sua estrutura contemporânea, códigos verbais e sonoros, ele se liga fortemente à imagem. Umberto Eco (1970) ao falar sobre a comunicação audiovisual, a define como um fenômeno complexo por apresentar a terceira articulação, ou seja, a articulação visual, que por sua vez interage com os sons e as palavras.

No ultimo século, é notável que a humanidade tem deixado suas marcas narrativas e multiculturais em imagens e sons interconectados de várias formas (BAPTISTA, 1995). Ainda segundo o mesmo autor, de fato na década de 60, o cinema assume uma nova dimensão pedagógica, acompanhando o próprio evoluir da sociedade e contribuindo para essa evolução. 
"Os conhecimentos transmitidos pelos veículos de comunicação audiovisual, principalmente através da televisão e do cinema, constituem aquilo que alguns autores têm chamado de um autêntico currículo paralelo, cujas implicações pedagógicas importam conhecer, estudar e investigar no próprio âmbito escolar, uma vez que interferem de forma direta no processo normal de ensino-aprendizagem - currículo institucional - quer no que diz respeito aos efeitos cognitivos mais específicos, quer no que toca a esfera mais global dos valores, atitudes e padrões de comportamento.” (SAPERAS, 1993).

Mas então, o que seria educação audiovisual? O que, especificamente, envolve a integração entre essa arte e o ensino? Segundo Joan Ferrés:

\begin{abstract}
"Uma educação audiovisual coerente e integral deve abranger as duas dimensões: a pedagogia da imagem e a pedagogia com imagem, ou seja, o audiovisual como objeto ou matéria de estudo e o audiovisual como recurso de ensino. A pedagogia da imagem (integrar na escola o audiovisual como matéria ou objeto de estudo) representa educar os alunos para aproximação crítica aos meios audiovisuais: a televisão, o cinema, a publicidade (...). A sociedade atual não pode falar de uma educação integral se os alunos ainda não alcançaram uma determinada capacidade para a análise crítica das mensagens emitidas por intermédio desses meios. Em uma sociedade na qual a comunicação audiovisual é hegemônica, pode-se afirmar que uma escola que não educa criticamente para a televisão é uma escola que não educa.” (FERRÉS, 1996:145).
\end{abstract}

De acordo com Carvalho (1998), o cinema de alguma forma reconstrói a vida social, uma vez que expressa e deixam registradas práticas sociais, modos de pensar, valores, símbolos, sentimentos, comportamentos, tensões, expectativas, temores, próprios de uma determinada sociedade. Abrem, então, novas perspectivas para que o homem conheça seu momento histórico, sua relação com outros homens, o como e o porquê os homens se educam, subsidiando a reconstrução histórica do objeto educação. Sendo assim, o vídeo em si pode se transformar em um importantíssimo recurso pedagógico uma vez que a experiência proporcionada representa uma função alternativa de disseminar a informação, tornando viável a exemplificação de conceitos até então abstratos, simplificando a compreensão da realidade, estimulando a concepção sobre fatos e acontecimentos e consequentemente tornando a realidade cada vez mais próxima.

Como o cinema é capaz de atingir tão profundamente criteriosas e importantes bases para o ensino e aprendizado, não basta apenas pegar um filme e repassá-lo de maneira aleatória; é fundamental conhecer o filme primeiramente em sua intenção, incluindo linguagem e abordagens sociológicas e psicológicas, para que depois estejamos capacitados para relacionar as características mais importantes desses canais de comunicação, juntamente com o campo que pretendemos atingir em termos de informação.

Além disso, é necessário, por parte dos professores, que desenvolvam cada vez mais em seus alunos a capacidade de interpretação, juntamente a uma postura crítica, em relação aos conteúdos administrados, pois só assim os resultados esperados pelo uso do cinema como estratégia serão eficazes no processo de ensino-aprendizado.

De acordo com Baptista (2005), apelar para a utilização desses meios pode ser algo muito digno, inovador, reformador, e até mesmo revolucionário. Mas utilizá-los na prática educativa é, em contrapartida, algo extraordinariamente complexo, com constantes implicações pedagógicas/ didáticas e por vezes mesmo científicas, quer na sua utilização curricular mais óbvia, quer em termos de compreensão intertextual menos previsível ou identificável.

Uma das primeiras questões a ser enfrentada por aqueles que trabalham com fontes fílmicas relaciona-se com a natureza das fontes utilizadas, visto que se está lidando com um "tipo específico de registro humano que precisa ser decodificado e interpretado." (NOMA, 1998).

“Diante do filme o pesquisador não mais “olha” com recolhimento, nem mesmo com distração, aborda-o na posição de um observador atento às associações de imagens e sons, a cada vestígio de significação como se caçasse um tesouro perdido em meio à experiência perceptiva do cinema”. (TOMAIM, 2004) 
Baptista (2005) ainda vai mais além e questiona quem irá transformar o professor, eventualmente interessado, num consistente cineclubista, num sagaz analista dos gêneros cinematográficos, num competente contextualizador de referências intertextuais, num conhecedor da história, das técnicas, das teorias e das correntes estéticas, num decodificador seguro de mensagens interculturais, políticas, econômicas, sociais, étnicas, éticas, estéticas e poéticas, em suma, num hábil leitor das linguagens fílmicas e conhecedor da arte cinematográfica em toda a amplitude dos seus dialetos?

Podemos entender assim que a necessidade de melhor preparação desses profissionais atuantes na área da educação é cada vez mais importante; não pela errônea ideia que o professor está ali somente para ser ouvido, mas sim por eles serem participantes de uma relação de troca, no nível das experiências, dos saberes, bem como do aprendizado cognitivo e integral. Para exemplificar, Freire (1996) afirma que ensinar não é transmitir conhecimento, mas permitir que o educando construa seu próprio saber... essa é a tarefa de todo educador.

Ensinar Ciências, ou qualquer outra disciplina, é um grande desafio para os educadores. Isso ocorre em virtude do caos em que o processo educacional em nosso país está mergulhado, tendo uma crescente desvalorização do professor e a mercadorização do ensino, banalizando, dessa forma, o processo de ensino-aprendizagem (NASCIMENTO, 2008).

Nessa perspectiva, através deste trabalho, procuramos direcionar nossa pesquisa de modo a adotá-la como uma estratégia didática, confiando ao professor o papel principal de mediador, para que este proporcione aos estudantes a possibilidade de reflexão sobre o que está contido nos livros e nas demais fontes de informação, relacionando as mesmas à leitura das imagens reveladas pelo cinema. Desta forma, ao associarmos o aprendizado científico com o cinematográfico, será possível que nossos alunos criem uma visão crítica e, ainda, contextualizada da sociedade que fazem parte.

Assim sendo, o presente estudo pode contribuir para a prática de utilização do cinema dentro da sala de aula como estratégia pedagógica e não somente como uma mera forma de entretenimento.

\section{METODOLOGIA}

A pesquisa foi do tipo descritiva, de campo, mista e utilizou como instrumento de coleta de dados um questionário (BARROS e LEHFELD, 2007).

Pesquisas mistas analisam os dados numéricos e valorizam a riqueza e diversidade das perguntas livres.

Utilizou-se o questionário por ser o instrumento mais usado para o levantamento de informações, além de possibilitar ao pesquisador abranger maior número de pessoas e de informações em curto espaço de tempo (BARROS e LEHFELD, 2007). O questionário foi preparado pelos autores deste trabalho de forma a buscar a maior quantidade possível de informações com o público-alvo, os professores.

O universo da pesquisa foi formado por 30 professores das disciplinas Ciências Naturais e Biologia, presentes em diversas escolas de educação básica da região metropolitana de Belo Horizonte, durante o primeiro semestre de 2011.

Os questionários foram distribuídos aos professores, público alvo dessa pesquisa, por alunos do curso de Ciências Biológicas da Pontifícia Universidade Católica de Minas Gerais, das unidades de Betim e Belo Horizonte. O questionário aplicado continha perguntas fechadas e abertas.

Antes da aplicação das questões explicou-se sobre os objetivos a que este instrumento se propunha, para que os professores fossem esclarecidos quanto à utilização dos mesmos. Todos os professores que participaram 
preencheram Termo de Consentimento Livre e Esclarecido. Depois de preenchidos, os questionários foram devolvidos aos autores da pesquisa para análise dos dados. É pertinente informar que toda a identificação de pessoa jurídica e/ou de pessoa física foi sigilosamente guardada e respeitou-se o fato de algumas pessoas optarem por não participar da pesquisa.

\section{RESULTADOS E DISCUSSÃO}

Foram preenchidos ao todo 30 questionários. Dos 30 professores, 22 são mulheres e 8 são homens. As idades variaram entre 22 a 60 anos de idade, sendo a média das idades correspondente a 36,7 anos.

Os resultados dessa pesquisa serão apresentados em números absolutos uma vez que facilitam o entendimento do número amostral total desse estudo.

A formação de todos os professores (30) é na área de Ciências Biológicas, sendo que 14 possuíam titulação máxima de graduação, 12 especialização e 4 mestrado. No âmbito da experiência profissional, sugere-se a análise da tabela 1, que apresenta o tempo que os professores atuam em sua profissão:

\begin{tabular}{|l|l|}
\hline Experiência Profissional (Anos) & Professores em números absolutos \\
\hline 0 a 5 anos & 8 \\
\hline 6 a 10 anos & 8 \\
\hline 11 a 15 anos & 7 \\
\hline 16 a 20 anos & 2 \\
\hline Mais de 20 anos & 5 \\
\hline \multicolumn{2}{|c|}{ Tabela 1: Tempo que os professores atuam em sua profissão. }
\end{tabular}

Um dos principais objetivos dessa pesquisa é detectar como o cinema é utilizado por esses professores como estratégia pedagógica. Nessa perspectiva, um dado bastante relevante para fundamentar alguns argumentos desse trabalho é considerar a frequência com que esses educadores planejam suas aulas. O gráfico 1 expressa em números absolutos essa freqüência:

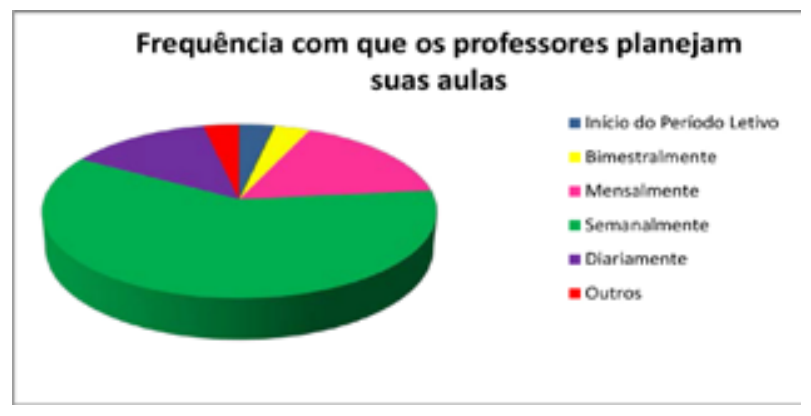

Outra questão muito importante a ser trabalhada com esses professores é a frequência com que eles utilizam a aula expositiva como estratégia. Apesar de existirem vários recursos inovadores, o presente estudo mostra que as aulas expositivas ainda são as mais utilizadas pela maioria dos professores.

Segundo Krasilchick (2004):

“... a Biologia pode ser uma das disciplinas mais relevantes e merecedoras da atenção dos alunos, ou uma das disciplinas mais insignificantes e pouco atraentes, dependendo do que for ensinado e de como isso foi feito". (KRASILCHICK, 2004) 
Sugerir outros tipos de estratégias não significa apontar as aulas expositivas como ineficazes, mas significa mostrar que outros recursos também podem ser de grande valia para o processo de ensino e aprendizagem. Além disso, um professor que mescla diferentes alternativas de forma criativa tem a probabilidade muito maior de envolver seus alunos de maneira mais intensa, comparado àquele professor que só utiliza o quadro negro e a oratória na maior parte do tempo. O gráfico 2 evidencia a frequência com que os professores utilizam as aulas expositivas como metodologia:

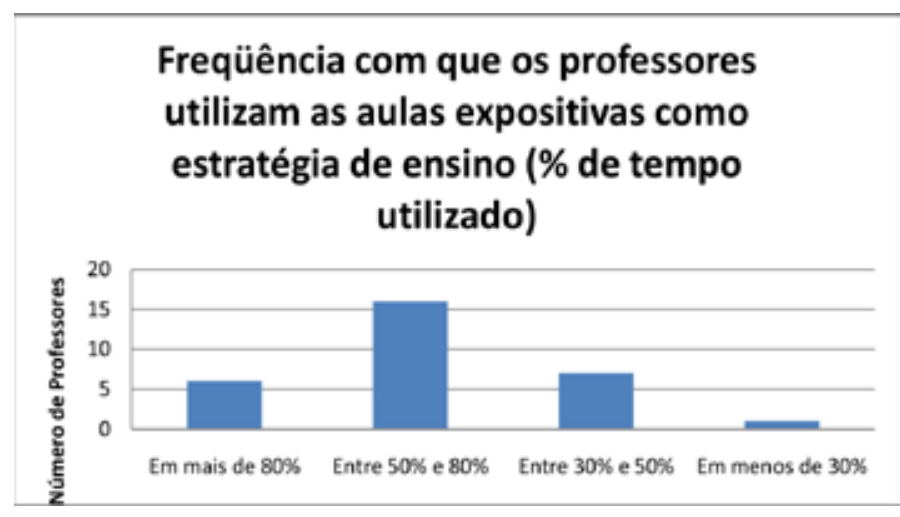

Após averiguar a freqüência da utilização das aulas expositivas perguntamos aos professores quais estratégias eram utilizadas para o enriquecimento de suas aulas. Como resultados obtivemos as informações apresentadas no gráfico 3:

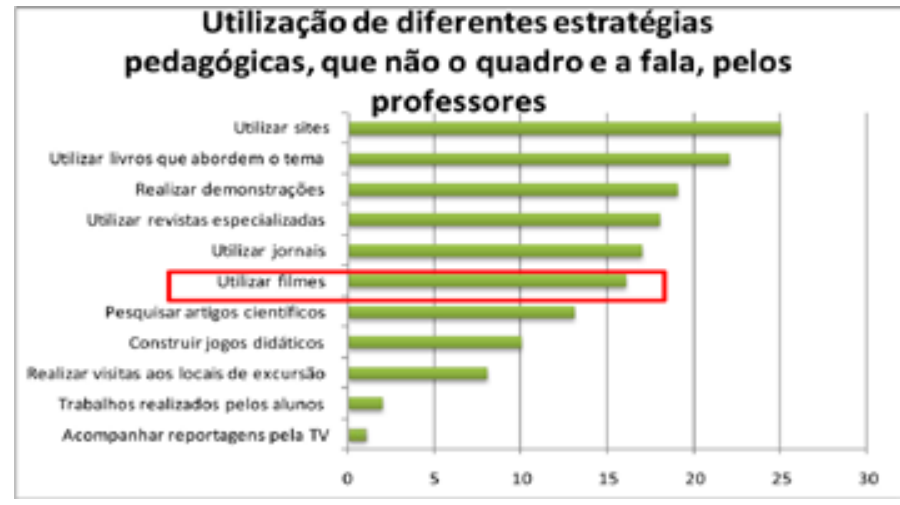

Podemos notar nesse ranking que o uso do cinema como estratégia de enriquecimento das aulas lecionadas por esses professores aparece apenas em $6^{\circ}$ lugar. Apesar de 16 professores, o que corresponde a mais da metade, utilizarem filmes como estratégia pedagógica para o enriquecimento de suas aulas, é necessário saber qual a frequência com que isso é feito, para não termos a ideia ilusória de que esse método é amplamente utilizado.

Foi investigada também a freqüência com que estes 16 professores utilizam a referida estratégia pedagógica (tabela 2):

\begin{tabular}{|l|l|}
\hline $\begin{array}{l}\text { Freqüência da utilização do cinema } \\
\text { como estratégia pedagógica }\end{array}$ & Professores (em números absolutos) \\
\hline Ao final das exposições de determinado conteúdo & 2 \\
\hline 4 vezes ao ano ( Corresponde a 1 filme por bimestre) & 3 \\
\hline 2 vezes ao ano (Corresponde a 1 filme por semestre) & 2 \\
\hline $\begin{array}{l}\text { Muito pouco (Menos de } 1 \text { filme por } \\
\text { semestre, ou seja, } 1 \text { filme por ano letivo) }\end{array}$ & 9 \\
\hline
\end{tabular}

Tabela 2: Frequência com que os professores utilizam o cinema como estratégia pedagógica. 
Podemos perceber então que apesar dos professores que utilizam o cinema serem a maioria, comparada a parcela de professores que não utilizam, ainda assim a frequência com que a atividade é realizada é muito baixa, pois 9 dentre esses 16 professores exibem aos seus alunos a média de apenas um filme por ano letivo, 3 professores trabalham filmes com seus alunos 4 vezes por ano, o que corresponde a 1 filme por bimestre, 2 professores trabalham filmes com seus alunos ao final da exposição dos conteúdos e 2 professores trabalham filmes com seus alunos 2 vezes ao ano, o que corresponde a 1 filme por semestre.

Ainda perguntamos aos professores quais eram os motivos pelos quais eles optavam por usar ou não o recurso.

Os professores que utilizam o método alegam que o uso dos filmes promove enriquecimento da aula, complementa e ilustra o conteúdo e podem também ter utilidade para os alunos como revisão da matéria.

Já os professores que não utilizam o método alegam que não o fazem por que é difícil apropriar o tempo do filme a carga horária da aula, porque não é todo conteúdo que necessita ser aprofundado com pesquisas e filmes, por problemas como a infraestrutura (falta de espaço e equipamento) e pelos alunos dispersarem muito.

Com base nas respostas dos professores, ainda investigamos quais eram as dificuldades mais encontradas no momento de utilizar o cinema como estratégia pedagógica. Cerca de 17 professores acreditam que a maior dificuldade é a falta de tempo, 7 professores atribuem as maiores dificuldades a outros motivos como a indisciplina dos alunos, dificuldade em alugar os filmes, e difícil agendamento da sala de vídeo, 6 professores alegam que a maior dificuldade é a falta de televisão, e 4 professores atribuem as maiores dificuldades a falta de aparelho de vídeo e DVD.

As informações acima, relatadas pelos professores da presente pesquisa, divergem das ideias de um estudo feito por Maestrelli e Ferrari (2006), que afirmam que a experiência em cursos de graduação e em cursos de formação continuada de professores tem mostrado que vários filmes comerciais podem ser adequadamente utilizados no ensino de genética, tanto no Ensino Superior como no Ensino Médio, e representam uma alternativa compatível às condições de ensino de grande parte das escolas públicas.

Já em relação a eficácia do recurso, o uso do filme pode sim ser muito proveitoso para o ensino e para a aprendizagem, se transmitido aos alunos de forma programada e correta. Por esse motivo, perguntamos aos professores se em algum momento de sua formação profissional houve alguma disciplina que estimulasse e orientasse o uso de filmes comerciais como estratégia pedagógica para o Ensino de Ciências e Biologia. Apenas 8 dos professores alegaram que sim e, portanto, 22 professores alegaram que nunca tiveram qualquer experiência de utilização do cinema para fins didáticos ao longo de sua formação profissional.

Portanto, é bastante provável que se houver um bom treinamento dos educadores é possível adotar o recurso com maior frequência e de forma muito eficaz; segundo Arroio (2007), o professor de ciências deve passar por um processo de educação do olhar que lhe possibilite "ler" as imagens do cinema. Para reafirmar essas informações podemos apresentar o discurso de um dos 8 professores que puderam ter essa experiência: “ $\mathrm{O}$ incentivo para utilização do cinema como estratégia pedagógica ao longo de toda formação profissional, de um modo geral, foi muito importante e refletiu em uma vivência bastante proveitosa”.

Para destacar o quão é importante a preparação adequada desses profissionais Rezende (2008) ressalta a importância do papel do professor na concretização deste método, já que, como exposto, é o referido mediador da orientação e apoio ao aluno, e então pode fazer dos materiais audiovisuais, recursos úteis para o ensino das Ciências.

Após entendermos a frequência com que o recurso é utilizado e a preparação que os profissionais da área da educação receberam ao longo de suas formações, é de extrema importância entendermos a maneira como 
esses professores utilizam essa estratégia pedagógica. Por essa razão, perguntamos aos docentes quais eram os critérios de escolha desses filmes, e então podemos analisar as respostas de acordo com o gráfico 4:

\section{Critérios de escolha dos filmes que serão utilizados como estratégia pedagógica}

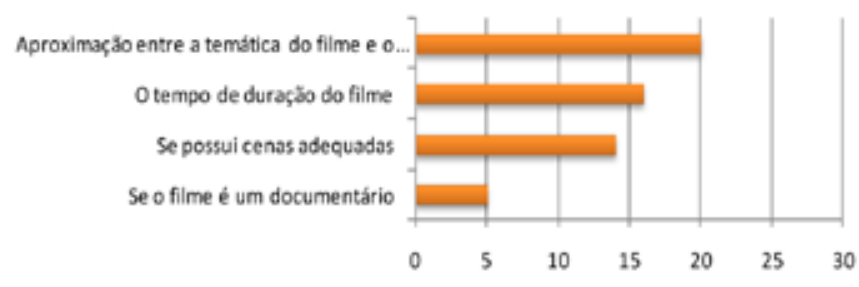

Para complementarmos essas informações, perguntamos aos professores qual era a aceitação e aproveitamento dos alunos a respeito do uso do cinema e pudemos perceber algumas diferenças entre as respostas. A maior parte dos professores afirma que: "Os alunos gostam do recurso, mas que encaram-no totalmente como uma fuga das aulas expositivas”. Outra parcela de professores acredita que: "Quando a aula é planejada com um roteiro e posteriormente com um momento para avaliação alguns alunos levam a sério a proposta com o intuito de aprendizagem, porém, outros alunos só encaram a estratégia como fuga também”. Esses professores alegam que a aceitação nunca é 100 \% positiva em relação ao ensino e a aprendizagem, mas de qualquer forma os alunos adoram independente da intenção de aprender ou da intenção de fugir do quadro negro. Já uma parcela um pouco menor afirma que: "Depende da turma, de suas motivações, do conteúdo, da relação entre professor e aluno, do tempo disponibilizado para a discussão antes e depois da exibição do filme, mas mesmo assim, em quase todos os casos, a intenção de fuga das aulas expositivas tem um peso considerável comparado à intenção de aprender efetivamente”. A minoria dos professores alega que: “A fuga para as aulas expositivas é um fator muito irrelevante e os debates pós-filme são calorosos e produtivos”. Desta forma, essa minoria acredita que o recurso é eficiente e proveitoso, independente de qualquer variável.

Indagamos ainda aos docentes qual a importância que eles atribuíam ao uso do cinema para o aprendizado geral na vida de seus alunos. Dezoito professores acreditam que o método pode ser eficaz para o ensino de qualquer disciplina escolar e para o desenvolvimento da criticidade dos alunos, 4 professores alegam que essa estratégia pedagógica pode contribuir para o ensino de qualquer disciplina escolar, e 3 professores acreditam que o uso do cinema pode contribuir para o ensino de ciências, de biologia e para o desenvolvimento da criticidade dos alunos. $\mathrm{O}$ somatório dos professores não é igual a 30, pois cinco questionários foram entregues com essa questão em branco.

Comparando essas informações com os dados de outros trabalhos podemos perceber a coerência dessas informações. Arroio, Diniz e Giordan (2005) registram que, de maneira geral, a integração de todos estes recursos audiovisuais na sala de aula de ciências, além de servir para organizar as atividades de ensino, serve também para o aluno desenvolver a competência de leitura crítica do mundo, colocando-o em diálogo com os diversos discursos veiculados pelo audiovisual.

Em uma outra pesquisa realizada por Viana (2009), percebeu-se a possibilidade de ensinar de forma interdisciplinar, com o uso de filmes comerciais, pois diferentemente do modo como a escola ainda persiste em ensinar, o conhecimento não se apresenta fragmentado. Com o uso dos filmes comerciais, que tratam de problemas e situações diversas, todos os conhecimentos se apresentam ao aluno de forma global, intrincados em uma rede de conhecimentos e significados.

O produto audiovisual pode ser um ótimo ponto de partida para uma série de debates sobre os mais diversos temas referentes à ciência, não apenas para romper as imagens deformadas da ciência e do método científico identificadas nos alunos, que são responsáveis, em grande parte, pelo desinteresse no aprendizado de ciências (Gallego Torres, 2007), mas também enriquecendo e ampliando estas concepções. 
O cinema atualmente pode ser trabalhado em prol de uma melhora na educação e essa tentativa não é recente. Um exemplo disso é que o cinema vem se relacionando com a educação do Brasil desde as décadas de 20 e 30. Isso se deu com a criação do INCE- Instituto Nacional de Cinema Educativo. O INCE foi criado pelo Poder Legislativo, em Janeiro de 1937, embora já viesse funcionando desde o ano anterior, tendo produzido, em 1936, cerca de 26 filmes científicos, de reportagem e de temática artística, como Lição de Taxidermia, filmado por Humberto Mauro no Museu Nacional (SIMIS, 1996 ; ANDRADE, 1962).

Como podemos notar o uso do cinema, apesar de ser uma prática antiga, ainda é pouco trabalhado como estratégia pedagógica e muitos fatores devem ser minuciosamente analisados. Não basta usarmos o recurso de forma aleatória, todo esse processo deve ser bem feito para obtenção de êxito.

Para finalizar, o uso adequado desta ferramenta pedagógica para aprimorar as práticas educativas depende também da qualificação dos profissionais da área. Essa eficácia do recurso ainda depende, como qualquer outra estratégia, da boa vontade do aluno na superação das dificuldades e na busca pelo conhecimento, que se traduz no interesse em aprender.

\section{CONSIDERAÇÕES FINAIS}

Após analisarmos os resultados da presente pesquisa percebemos que o cinema ainda é pouco utilizado como estratégia pedagógica para o ensino de Ciências e Biologia.

Assim, essa iniciativa deve ser repensada de forma cautelosa para que seja implantada com sucesso no ensino, visando a minimização da utilização do cinema apenas como uma válvula de escape das aulas expositivas.

O uso do cinema deve ser entendido como uma estratégia tão completa quanto todas as outras mais tradicionais ao invés de ser vista apenas como algo complementar.

Ao pretender divulgar, incentivar e viabilizar o uso do cinema geramos uma lista de 83 filmes que podem ser utilizados no ensino de Ciências e Biologia, oferendo também os possíveis conteúdos que podem ser trabalhados em cada filme.

A lista encontra-se em anexo no presente trabalho. Os filmes foram sugeridos pelos professores que responderam ao questionário (instrumento de coleta de dados) e pelos autores desse trabalho. 


\section{REFERÊNCIAS BIBLIOGRÁFICAS}

ACHBAR, Mark; ABBOTT, Jennifer. The Corporation. Canadá: Big Pictures Media Corporation, 2004.1 vídeodisco (145 minutos): NTSC: son.,color.

ALLERS, Roger; MINKOFF, Rob. The Lion King (O Rei Leão). Estados Unidos: Walt Disney Productions, 1994.1 vídeo-disco (88 minutos): NTSC: son.,color.

AMIEL, Jon. Criação. Estados Unidos: Ocean Pictures / BBC Films/ UK Film Council / Recorded Picture Company, 2009.1 vídeo-disco (108 minutos): NTSC: son.,color.

AMIEL, Jon. The Core (O núcleo - Missão ao Centro da Terra). Estados Unidos: Horsepower Films / Core Prods. Inc., Paramount Pictures / UIP, 2003.1 vídeo-disco (135 minutos): NTSC: son.,color.

ANDRADE, Rudá de. Cronologia da Cultura Cinematográfica no Brasil (Cadernos da Cinemateca 1). São Paulo: Fundação Cinemateca Brasileira, 1962.

ANNAUD, Jean Jacques. A guerra do fogo (La Guerre du Feu). França - Canadá, 1981.1 vídeo-disco (100 minutos): NTSC: son.,color.

ARROIO, Agnaldo. The role of cinema into science education. In: Science Education in a Changing Society. Lamanauskas, V. (Ed.). Siauliai: Scientia Educologica, 2007.

ARROIO, Agnaldo; DINIZ, Manuela Lustosa.; GIORDAN, Marcelo. A utilização do vídeo educativo como possibilidade de domínio da linguagem audiovisual pelo professor de Ciências. VEncontro Nacional de Pesquisa em Educação em Ciências - V ENPEC - ATAS. Bauru: ABRAPEC, 2005.

BAPTISTA, Vitor Reis. Pedagogia da Comunicação, Cinema e Ensino: Dimensões Pedagógicas do Cinema. Universidade do Algarve, 1995. Disponível em: www.bocc.ubi.pt. Acesso em 03/03/2011.

BAPTISTA, Vitor Reis. Linguagens Fílmicas, Cinema e Pedagogia da Comunicação. Universidade do Algarve, 2005. Disponível em: www.bocc.ubi.pt. Acesso em 05/03/2011.

BARROS, Aidil Jesus da Silveira; LEHFELD, Neide Aparecida de Souza. Fundamentos de metodologia científica. 3. ed. São Paulo: Pearson/Prentice Hall, 158 p., 2007.

BAY, Michel. The Island (A Ilha). EUA: DreamWorks SKG / Warner Bros./ Parkes/MacDonald Productions, 2005. 1 vídeo-disco (127 minutos): NTSC: son.,color.

BLOCH, Sérgio; LAMARCA, Tânia. Tainá - Uma Aventura na Amazônia. Brasil: Tietê Produções, 2000.1 vídeo-disco (90 minutos): NTSC: son.,color.

BRANAGH, Kenneth. Mary Shelley’s Frankenstein (Frankenstein de Mary Shelley). Estados Unidos: Columbia, 1994.1 vídeo-disco (118 minutos): NTSC: son.,color.

BREVIG, Eric. Journey to the Center of the Earth (Viagem ao centro da Terra). Estados Unidos: Walden Media / New Line Cinema, 2008.1 vídeo-disco (92 minutos): NTSC: son.,color.

BURTON, Tim. O planeta dos macacos. Estados Unidos: Fox Film Corporation, 2001.1 vídeo-disco (120 minutos): NTSC: son.,color.

CAFFÉ, Eliane. Narradores de Javé. Brasil: Bananeira Filmes / Gullane Filmes / Laterit Productions, Riofilme, 2003.1 vídeo-disco (100 minutos): NTSC: son.,color.

CAMERON, James. Avatar. Estados Unidos: Twentieth Century-Fox Film Corporation / Lightstorm Entertainment / Giant Studios, 2009.1 vídeo-disco (150 minutos): NTSC: son.,color. 
CARLOS, Saldanha. Rio. Estados Unidos: Blue Sky Studios | Twentieth Century Fox Animation, 2011.1 vídeodisco (96 minutos): NTSC: son.,color.

CARVALHO, Elma Júlia Gonçalves de. Cinema, História e Educação. Revista Teoria e Prática da Educação, v. 3, n 5, p. 121-131, Set/1998.

CLARK, Larry. Kids. Estados Unidos: Miramax Films, 1995.1 vídeo-disco (96 minutos): NTSC: son.,color.

COPPENS, Yves. L’Odyssée de L’Espèce (A odisséia da espécie). França: Discovery Channel, 2003.1 vídeodisco (89 minutos): NTSC: son.,color.

DARNELL, Eric, GUTERMAN, Lawrence. Antz (Formiguinhaz). Estados Unidos: Dream Works, 1998.1 vídeodisco (82 minutos): NTSC: son.,color.

DARNELL, Eric; MCGRATH, Tom. Madagascar. Estados Unidos: DreamWorks SKG / Pacific Data Images, 2005.1 vídeo-disco (80 minutos): NTSC: son.,color.

DAVIS, John A. Lucas um intruso no formigueiro. Estados Unidos: Warner Bros. Pictures / Playtone / DNA Productions Inc. / Legendary Pictures, 2006. 1 vídeo-disco (88 minutos): NTSC: son.,color.

DEMME, Jonathan. Filadélfia. Estados Unidos: TriStar Pictures / Clinica Estetico, 1993.1 vídeo-disco (125 minutos): NTSC: son.,color.

DIETERLE, Willian. A história de Louis Pasteur. Estados Unidos, 1936.1 vídeo-disco (86 minutos): NTSC: son., preto e branco.

DORMAEL, Jaco Van. Le huitième jour (O oitavo dia). França, Bélgica: Europa Home Video, 1995.1 vídeodisco (118 minutos): NTSC: son.,color.

ECO,Umberto. Semiologie des messages visuels. Revue Comunicatinos, n.15, 1970, p.41-48. Disponível em: http://www.persee.fr/web/revues/home/prescript/article/comm_0588-8018_1970_num_15_1_1213. Acesso em 08/03/2011.

EDEL, Uli. Eu Christiane F., treze anos, drogada e prostituída. Alemanha, 1981.1 vídeo-disco (125 minutos): NTSC: son.,color.

EMMERICH, Roland. The day after tomorrow (O dia depois de amanhã).Estados Unidos: Fox Film Corporation, 2004.1 vídeo-disco (124 minutos): NTSC: son.,color.

FARRELLY, Peter; FARRELY, Bob; KROON, Piet; SITO, Tom. Osmosis Jones (Osmose Jones - Uma viagem ao corpo humano). Estados Unidos: Warner, 2001. 1 vídeo-disco (95 minutos): NTSC: son.,color.

FERRÉS, Joan. Vídeo e Educação. Porto Alegre: Artes Médicas, 1996.

FOX, Louis. The history of stuff (A história das coisas). EUA, 2005. 1 vídeo-disco (25 minutos): NTSC: son.,color.

FRANKEINHEIMER, John. The Burning Season (Amazônia em Chamas). Estados Unidos, 1994.1 vídeo-disco (123minutos): NTSC: son.,color.

FRANKEINHEIMER, John. The island. of Dr. Moreau (A ilha de Dr. Moreau). Estados Unidos: New line, 1996.1 vídeo-disco (100minutos): NTSC: son.,color.

FREIRE, Paulo. Pedagogia da Autonomia: saberes necessários à prática educativa. 31ª ed. São Paulo: Paz e Terra, 1996.

FURTADO, Jorge. Ilha das flores. Brasil: Casa de Cinema de Porto Alegre, 1989.1 vídeo-disco (12 minutos): NTSC: son.,color.

FUZELLIER, Étienne. Cinéma et littérature. Paris, Ed du Cerf, Coll., 217p, 1964. 
GALLEGO TORRES, Adriana Patricia. Imagen popular de la ciencia transmitida por los cómics. Revista Eureka sobre Enseñanza y Divulgación de las Ciencias, v. 4, n. 1, p. 141-51, 2007.

GARANT, Ben; LENNON, Thomas. Night at the Museum (Uma noite no museu). Estados Unidos: 20th Century Fox Film Corporation / 1492 Pictures / 21 Laps Entertainment, 2006.1 vídeo-disco (108 minutos): NTSC: son.,color.

GEORGE, Miller. Lorenzo’s Oil (O óleo de Lorenzo). Estados Unidos: Universal Pictures / UIP, 1992.1 vídeodisco (135 minutos): NTSC: son.,color.

GUGGENHEIM, Davis. An Inconvenient Truth (Uma verdade inconveniente). Estados Unidos: Lawrence Bender Productions / Participant Productions, 2006.1 vídeo-disco (100 minutos): NTSC: son.,color.

HAMM, Nick. O enviado. Estados Unidos, Canadá: Imagem Filmes, 2003.1 vídeo-disco (100 minutos): NTSC: son.,color.

HICKNER, Steve; SMITH, Simon J. Bee movie. Estados Unidos: DreamWorks SKG / Pacific Data Images / Columbus 81 Productions, 2007.1 vídeo-disco (90 minutos): NTSC: son.,color.

HOWARD, Ron. A beautiful mind (Uma mente brilhante). Estados Unidos: Universal, 2001.1 vídeo-disco (135 minutos): NTSC: son.,color.

JOHNSTON, Joe. Jurassic Park III (Parque dos Dinossauros III). Estados Unidos: Universal, 2001.1 vídeodisco (93 minutos): NTSC: son.,color.

JOHNSON, Tim; KIRKPATRICK, Karey. Over de Hedge (Os sem floresta). Estados Unidos: DreamWorks SKG, 2006. 1 vídeo-disco (83 minutos): NTSC: son.,color.

KRASILCHICK, Myriam. Práticas de Ensino de Biologia. - 4ª ed. - São Paulo: Edusp, 197 p. 2004.

KUROSAWA, Akira. Sonhos. Japão, Estados Unidos: Warner, 1990.1 vídeo-disco (120 minutos): NTSC: son.,color.

LASSETER, John. A bug's life (Vida de inseto). Estados Unidos: Pixar Animation Studios / Walt Disney Productions, 1998.1 vídeo-disco (96 minutos): NTSC: son.,color.

LEIGHTON, Eric; ZONDAG, Ralph. Dinosaur (Dinossauro).Estados Unidos: Walt Disney Productions, 2000.1 vídeo-disco (82 minutos): NTSC: son.,color.

LEVINSON, Barry. Rain Man. Estados Unidos: Fox Film Corporation, 1988.1 vídeo-disco (133 minutos): NTSC: son.,color.

MAESTRELLI, Sylvia Regina Pedrosa; FERRARI, Nadir. O óleo de Lorenzo: o uso do cinema para contextualizar o ensino de genética e discutir a construção do conhecimento científico. Genética na Escola, ano 1, vol.2, p.3539, 2006.

MANN, Michael. O informante. Estados Unidos: Buena Vista Pictures, 1999.1 vídeo-disco (160 minutos): NTSC: son.,color.

MEIRELLES, Fernando. The Constant Gardener (O jardineiro fiel). Estados Unidos: Focus Features / Scion Films Limited / Potboiler Productions Ltd, 2005.1 vídeo-disco (129 minutos): NTSC: son.,color.

MESA, Willian. DNA - Caçada ao Predador. Estados Unidos: Interlight, 1997.1 vídeo-disco (92 minutos): NTSC: son.,color.

MEYER, Nicholas. The day after (O dia seguinte). Estados Unidos: Video Ban, 1983.1 vídeo-disco (126minutos): NTSC: son.,color. 
MILLER, Georg. Happy Feet - O pinguim. Estados Unidos: Village Roadshow Pictures / Kingdom Feature Productions / Animal Logic / Kennedy Miller Productions, Warner Bross, 2006.1 vídeo-disco (98 minutos): NTSC: son.,color.

NASCIMENTO, Vera Lúcia de. Revista Urutágua - Revista acadêmica multidisciplinar - DCS/UEM - nº 16 ago./set./out./nov. 2008 - Quadrimestral - Maringá - Paraná - Brasil. Disponível em: http://www.urutagua.uem. br/016/16nascimento.htm . Acesso em 08/03/2011.

NELSON, Jessie. I am Sam ( Uma lição de amor).Estados Unidos: PlayArte, 2001.1 vídeo-disco (133 minutos): NTSC: son.,color.

NICCOL, Andrew. Gattaca - A experiência genética. Estados Unidos: Columbia, 1997.1 vídeo-disco (106 minutos): NTSC: son.,color.

NOMA, Amélia Kimiko. Visualidades da vida urbana: Metrópolis e Blade Runner. São Paulo, Pontifícia Universidade Católica, Tese de Doutorado em História Social, 1998.

PEN, Sean. Into the wild (Na natureza selvagem). Estados Unidos: Paramount Vantage / Art Linson Productions / River Road Films / Into the Wild, 2007.1 vídeo-disco (140 minutos): NTSC: son.,color.

PERENNOU, Marie; NURIDSANY, Claude. Microcosmos- Le peuple de l'herbe (Microcosmos- Fantástica aventura da natureza).França: Mundial Filmes, 1996.1 vídeo-disco (77 minutos): NTSC: son.,color.

PETERSEN, Wolfgang. Outbreak (Epidemia).Estados Unidos: Warner Bros. / Punch Productions, 1995.1 vídeodisco (128 minutos): NTSC: son.,color.

RATNER, Brett. X3: X-Men III The Last Stand (X-Men III : O confronto final). Estados Unidos: 20th Century Fox / Marvel Enterprises / Ingenious Film Partners / Donners’ Company, 2006.1 vídeo-disco (103 minutos): NTSC: son.,color.

RAYMOND, Bradley. The Lion King III: Hakuna Matata (O Rei Leão III: Hakuna Matata). Estados Unidos: Walt Disney Productions, 2004.1 vídeo-disco (81 minutos): NTSC: son.,color.

REGGIO, Godfrey. Koyaanisqatsi - Uma vida fora do equilíbrio. Estados Unidos: Island Pictures, 1983.1 vídeodisco (87 minutos): NTSC: son.,color.

REZENDE, Luiz Augusto. História das Ciências no Ensino de Ciências: contribuições dos recursos audiovisuais. Núcleo de Tecnologia Educacional para a Saúde. Universidade Federal do Rio de Janeiro: Ciência em Tela, 2008.Vol.1.

ROONEY, Darrel; LADUCA, Rob. The Lion King II: Simba's Pride (O Rei Leão II: o reino de Simba). Estados Unidos: Walt Disney Productions, 1998.1 vídeo-disco (81 minutos): NTSC: son.,color.

ROSTEN, Irwin. The incredible machine (A incrível máquina humana).EUA: National Geographic video/ Wolper productions, 1989. 1 vídeo-disco (60 minutos): NTSC: son.,color.

SALDANHA, Carlos; THURMEIER, Mike. Ice Age 3 : Dawn of the Dinosaurs (A era do gelo 3).Estados Unidos: 20th Century Fox Film Corporation, 2009.1 vídeo-disco (96 minutos): NTSC: son.,color.

SAPERAS, Enric. Os Efeitos Cognitivos da Comunicação de Massas. Ed Asa, Lisboa, 1993. Disponível em: www.bocc.ubi.pt. Acesso em 03/03/2011.

SCOTT, Ridley. Blade Runner (O caçador de androides).Estados Unidos: Warner, 1982.1 vídeo-disco (117 minutos): NTSC: son.,color.

SCHAFFNER, Franklin. Os meninos do Brasil. Estados Unidos: Martin Richards, 1978.1 vídeo-disco (127 minutos): NTSC: son.,color. 
SHADYAC, Tom. Patch Adams - O amor é contagioso. Estados Unidos: Universal, 1998.1 vídeo-disco (115 minutos): NTSC: son.,color.

SILVA, Salete Terezinha de Almeida; CITELLI, Adilson (coordenador). Outras linguagens na escola: publicidade, cinema e tv, rádio, jogos, informática. 4. Ed.- São Paulo: Cortez, v.6, p.81- 108, 2004.

SIMIS, Anita. Estado e Cinema no Brasil. São Paulo: Annablume, 1996.

SINGER, Bryan. X-Men. Estados Unidos: 20th Century Fox / Marvel Films, 2000.1 vídeo-disco (105 minutos): NTSC: son.,color.

SINGER, Bryan. X2: X-Men United. Estados Unidos: 20th Century Fox / Marvel Entertainment / Donner/ Schuler-Donner Productions, 2003.1 vídeo-disco (134minutos): NTSC: son.,color.

SPIELBERG, Steven. A.I - Artificial intelligence (Inteligência artificial). Estados Unidos: Warner, 2001.1 vídeodisco (145 minutos): NTSC: son.,color

SPIELBERG, Steven. Jurassic Park - Parque dos Dinossauros. Estados Unidos: Universal, 1993.1 vídeo-disco (127 minutos): NTSC: son.,color.

SPIELBERG, Steven. Jurassic Park II - The Lost World (Parque dos Dinossauros II - O mundo perdido). Estados Unidos: Universal, 1997.1 vídeo-disco (129 minutos): NTSC: son.,color.

SPOTTISWOODE, Roger. And the band played on (E a vida continua). Estados Unidos: Odessa Home Video, 1993.1 vídeo-disco (136 minutos): NTSC: son.,color.

SPOTTISWOODE, Roger. The $6^{\circ}$ day (O sexto dia). Estados Unidos: Columbia, 2000.1 vídeo-disco (127 minutos): NTSC: son.,color.

SPURLOCK, Morgan; ISAACS, Daryl. Super Size Me - A dieta do palhaço. Estados Unidos: Samuel Goldwyn Films / Imagem Filmes, 2004.1 vídeo-disco (98 minutos): NTSC: son.,color.

STANTON, Andrew. Finding Nemo (Procurando Nemo). Estados Unidos: Pixar Animation Studios / Walt Disney Pictures, 2003.1 vídeo-disco (101 minutos): NTSC: son.,color.

STANTON, Andrew. Wall-E. Estados Unidos: Walt Disney Pictures / Pixar Animation Studios, 2008.1 vídeodisco (97 minutos): NTSC: son.,color.

STEINBERG, Gustavo; MASAGÃO, Marcelo. 1,99 Um Supermercado que vende palavras. Brasil: Marcelo Masagão, 2003.1 vídeo-disco (72 minutos): NTSC: son.,color.

THOMAS, Betty. 28 Days (28 Dias). Estados Unidos: Columbia Pictures Corporation / Tall Trees, 2000.1 vídeodisco (103 minutos): NTSC: son.,color.

TOMAIM, Cássio dos Santos. Cinema: um olhar fabricado - Como lidar com um objeto que responde aos nossos anseios afetivos e perceptivos. In: XVII Encontro Regional de História - O lugar da História. ANPUH/ SP -UNICAMP. Campinas, 6 a 10 de setembro de 2004. Disponível em: http://www.anpuhsp.org.br/downloads/ CD\%20XVII/artigos.html. Acesso em: 08/3/2011.

TRUMBULL, Douglas. Silent Running (Corrida Silenciosa). Estados Unidos: Universal, 1972.1 vídeo-disco (89 minutos): NTSC: son.,color.

TURTELTAUB, Jon. Instinct (Instinto). Estados Unidos: Touchstone Pictures / Spyglass Entertainment, 1999.1 vídeo-disco (127 minutos): NTSC: son.,color.

TV CULTURA. Série Água - O desafio do Século XXI, 1997.NTSC: son.,color.

TV CULTURA. Série Os pequenos leões da Mata Atlântica, 1993. NTSC: son.,color. 
TV CULTURA. Série Água - Um bem limitado, 1997.NTSC: son.,color.

TV CULTURA. Série Mar a vista - Uma viagem pelo litoral brasileiro, 1998. NTSC: son.,color.

VERBINSKI, Gore; WELLS, Simon. The time machine (A Máquina do tempo) EUA: Dream Works, 2002.1 vídeo-disco (96 minutos): NTSC: son.,color.

VIANA, Sandra da Silva. O Uso do cinema como ferramenta pedagógica para o ensino de Ciências na Modalidade Educação de Jovens e Adultos. Programa de Pós-Graduação Stricto Sensu em Ensino de Ciências do Campus de Nilópolis do Instituto Federal de Educação, Ciência e Tecnologia do Rio de Janeiro, 84.p., 2009.

WARGNIER, Régis. O Elo Perdido. França África do Sul, Inglaterra: Skyline Films / Vertigo / France 2 Cinéma / France 3 Cinéma / Boréales / TPS Star / The Imaginarium, Wild Bunch, 2005.1 vídeo-disco (122 minutos): NTSC: son.,color.

WEDGE, Chris; SALDANHA, Carlos. Ice Age (A era do gelo). Estados Unidos: 20th Century Fox Film Corporation, 2002.1 vídeo-disco (115 minutos): NTSC: son.,color.

WEDGE Chris; SALDANHA, Carlos. Ice Age 2: The Meltdown (A era do gelo 2: o degelo).Estados Unidos: 20th Century Fox Film Corporation, 2006.1 vídeo-disco (91 minutos): NTSC: son.,color.

WIEMER, Robert. Anna to the infinit power (Anna de infinito poder). Estados Unidos, 1982.1 vídeo-disco (105 minutos): NTSC: son.,color.

ZEMECKIS, Robert. Contact (Contato).Estados Unidos: Warner, 1997.1 vídeo-disco (150 minutos): NTSC: son.,color. 


\section{ANEXO}

Sugestões de filmes, noticiários e documentários que podem ser trabalhados nas disciplinas de Ciências e Biologia:

1. A.I - Inteligência artificial - (engenharia genética, bioética e tecnologia)

2. A era do gelo (I, II e III) - (mudanças climáticas, evolução, extinção das espécies, biodiversidade das geleiras, eras geológicas)

3. A guerra do fogo - (evolução)

4. A história das coisas - (sistema de extração de matéria prima, produção, consumo e lixo)

5. A história de Louis Pasteur (microbiologia, vírus, vacina, doenças)

6. A ilha - (clonagem, genética, ética, biotecnologia)

7. A ilha de Dr. Moreau - (engenharia genética, bioética e tecnologia)

8. A incrível máquina humana - (corpo humano, fisiologia)

9. A máquina do tempo - (ecologia e evolução)

10. A odisséia da espécie - (evolução humana, nossos antepassados, o andar bípede)

11. Amazônia em chamas - (questão dos seringueiros, conservação)

12. Anna de infinito poder - (engenharia genética, bioética e tecnologia)

13. Avatar - (degradação ambiental, extração de recursos, biodiversidade, preservação, interação do homem com o meio ambiente)

14. Bee movie - (biodiversidade, conservação)

15. Blade Runner - O caçador de androides - (engenharia genética, bioética e tecnologia)

16. Contato - (astronomia)

17. Corrida Silenciosa - (ecologia, preservação e degradação ambiental)

18. Criação - (teoria de evolução das espécies, Charles Darwin)

19. Dinossauro - (paleontologia, evolução, extinção de espécies)

20. DNA - Caçada ao predador - (bioquímica, imunologia, engenharia genética)

21. E a vida continua - (saúde, Aids, preconceito)

22. Epidemia - (vírus, doença, epidemia) 
23. Eu Christiane F., treze anos, drogada e prostituída - (drogas, sexualidade, cuidados com o corpo)

24. Filadélfia - (aids, preconceito)

25. Formiguinhaz - (ecologia, biodiversidade de invertebrados)

26. Frankenstein de Mary Shelley - (engenharia genética, bioética e tecnologia)

27. Gattaca - A experiência genética - (engenharia genética, bioética e tecnologia)

28. Happy Feet - O pinguim (ecologia, atrativos de reprodução, preconceito)

29. Ilha das flores - (ecologia, consumismo, desperdício, lixo)

30. Instinto - (ecologia)

31. Jurassic Park (I, II, III) - (paleontologia, evolução, extinção das espécies, engenharia genética, bioética e tecnologia)

32. KIDS - (drogas, sexualidade)

33. Koyaanisqatsi - Uma vida fora do equilíbrio - (ecologia)

34. Lucas um intruso no formigueiro - (comunidade de formigas, relações ecológicas)

35. Madagascar - (cadeia alimentar, biodiversidade, interação entre as espécies, reintrodução de animais cativos ao habitat natural)

36. Microcosmos - fantástica aventura da natureza (biodiversidade)

37. Na natureza selvagem - (sobrevivência, primeiros socorros, preservação da natureza)

38. Narradores de javé - (questões culturais e ambientais)

39. O dia depois de amanhã - (questões climáticas)

40. O dia seguinte - (guerra nuclear)

41. O elo perdido - (evolução)

42. O enviado - (engenharia genética, bioética e tecnologia)

43. O informante - (saúde tabaco, vício)

44. O jardineiro fiel - (ética, doenças parasitarias, aids, desnutrição, pobreza)

45. O núcleo - Missão ao centro da Terra - (movimento de rotação da Terra, magnetismo)

46. O oitavo dia - (genética, Síndrome de Down)

47. O óleo de Lorenzo - (doenças genéticas, bioquímica, sistema nervoso, doenças degenerativas) 
48. O planeta dos macacos - (evolução, preservação, ecologia)

49. O sexto dia - (clonagem, engenharia genética, bioética e tecnologia)

50. Os meninos do Brasil - (engenharia genética, bioética e tecnologia)

51. Os sem florestas - (perda de habitats, urbanização, biodiversidade, ecologia)

52. Osmose Jones - (sistema imunológico, bioquímica, fisiologia)

53. O Rei Leão (I, II e III) - (biodiversidade, cadeia alimentar, comportamento animal, ecologia, interação entre espécies)

54. Patch Adams - o amor é contagioso - (saúde, saúde mental)

55. Procurando Nemo - (biodiversidade presente nos ecossistemas marinhos, interações ecológicas)

56. Rain man - (saúde, saúde mental, autismo)

57. Rio - (animais em cativeiro, reprodução de animais cativos, tráfico de animais)

58. Série Água - O desafio do século XXI - TV Cultura (ecologia, preservação)

59. Série Água - Um bem limitado- TV Cultura ( ecologia, preservação)

60. Série Mar a vista- Uma viagem pelo litoral brasileiro - TV Cultura (ecologia, biodiversidade marinha, formações geológicas das costas brasileiras, manguezais)

61. Série Os pequenos leões da Mata Atlântica - TV Cultura (ecologia, preservação dos micos-leões remanescentes da Mata Atlântica)

62. Sonhos - (degradação do meio ambiente, biodiversidade, ecologia, importância da preservação ambiental, guerra nuclear)

63. Super size me - A dieta do palhaço - (obesidade, hipertensão arterial, diabetes, diet x light, alimentos, nutrientes, digestão)

64. Tainá - Uma aventura na Amazônia - (biodiversidade, ecologia)

65. The Corporation - (desenvolvimento humano e tecnologia)

66. Uma lição de amor - (saúde, saúde mental)

67. Uma mente brilhante - (saúde, saúde mental, esquizofrenia)

68. Uma noite no museu - (paleontologia, comportamento animal, biodiversidade)

69. Uma verdade inconveniente - (clima, aquecimento global, mudança climática e seus efeitos nos ecossistemas)

70. Viagem ao centro da Terra - (extinção, biodiversidade, preservação) 
71. Vida de inseto - (biodiversidade de invertebrados, relações ecológicas)

72. X-Men - (I, II e III) - (genética e engenharia genética)

73. Wall-E - (lixo, obesidade, consumismo, reciclagem)

74. 1,99 - Um supermercado que vende palavras- (consumismo)

75. 28 dias - (Saúde, consumo de álcool, reabilitação) 